\title{
Interfacing Forest Engineering with Bioenergy Production
}

\author{
James H. Dooley, PhD, PE \\ Forest Concepts, LLC \\ 3320 West Valley Hwy. N., Ste. D110, Auburn, WA 98001 \\ Written for presentation at the \\ 2008 ASABE Annual International Meeting \\ Sponsored by ASABE \\ Rhode Island Convention Center \\ Providence, Rhode Island \\ June 29 - July 2, 2008
}

\begin{abstract}
Woody biomass from forestland, urban greenbelts, and residential areas has the potential to provide more than 150 million tons per year of cellulosic feedstocks for biorefineries, pellet fuels, and fermentation. Production sites range from urban lots to large wildland forest tracts. Destinations range from small urban boutiques to large remote industrial complexes. The systems, logistics and equipment will need to be matched to the context of each combination of source and destination. This paper offers a discussion and postulates an operational context for planning equipment, business models, and logistics systems that may represent the likely evolution of the woody biomass feedstock industry. The context includes thousands of very small producers and users, and a continuum toward a few very large industrial complexes. Forest engineers are the logical engineering professionals to expanding their practices to include urban sources and new woody biomass uses. $A$ premise is that forest engineers are well equipped to address issues of materials collection, handling, preprocessing into commercially valuable feedstocks, and transportation systems to move large volumes of woody biomass to market.
\end{abstract}

Keywords. Biomass, bioenergy, forest engineering, planning, product definition.

The authors are solely responsible for the content of this technical presentation. The technical presentation does not necessarily reflect the official position of the American Society of Agricultural and Biological Engineers (ASABE), and its printing and distribution does not constitute an endorsement of views which may be expressed. Technical presentations are not subject to the formal peer review process by ASABE editorial committees; therefore, they are not to be presented as refereed publications. Citation of this work should state that it is from an ASABE meeting paper. EXAMPLE: Author's Last Name, Initials. 2008. Title of Presentation. ASABE Paper No. 08----. St. Joseph, Mich.: ASABE. For information about securing permission to reprint or reproduce a technical presentation, please contact ASABE at rutter@asabe.org or 269-429-0300 (2950 Niles Road, St. Joseph, MI 49085-9659 USA). 


\section{Introduction}

Woody biomass is a core element of our nation's strategy to replace imported oil and natural gas with renewable resources. Approximately 200 million tons of wood waste is generated by the forest products and paper industries with most of which is being used for co-products or energy. Additionally, more than one hundred million tons of woody biomass is available, but not currently used, per year from forest management, wildfire fire protection, and urban woody debris (Perlack et al. 2005). As forested landscapes in rural and urban areas are more intensively managed in the future, the amount of available woody biomass will increase.

The Western Governors' Association January 2006 task force report concludes that 35\% of the biomass available for power generation in the West must come from urban areas (Western Governors' Association 2006). Perlack, et al. estimate the urban woody debris to total 62 million tons per year, of which 28 million tons per year is available for diversion from landfills and compost. [Note that in this paper we are using the term tons without specifying whether the units are U.S. or SI due to the low resolution of our estimates.] Most of the currently non-recycled urban-source woody biomass is in the form of brush, branches, storm debris, and small trees. Urban wood waste from construction, demolition, commerce and industry may be diverted from current uses to new biofuels or bio-based products as the markets mature.

Recent national and local emphasis on community wildfire protection in the wildland-urban intermix is dramatically increasing the amount of woody biomass available from urban and suburban landscapes. Stimulated by funding from the National Fire Plan and the Healthy Forests Restoration Act, community wildfire prevention councils are active in most states. As such, very large volumes of woody biomass are potentially available for bioenergy and biobased products. Perlack, et al. estimated this component to be 60 million tons per year.

Bioenergy facilities (combustion power or cogeneration) are a major outlet for urban-source woody biomass. For example, King County, Washington, reports that more than 160,000 tons per year of woody biomass is processed into hog fuel for use by regional power and steam plants (Beatty et al. 2004). The "billion ton vision" (Perlack, Wright et al. 2005) for national biomass energy and biobased economy did not factor in biomass from wildfire protection and fuels reduction programs.

Today, the dominant commercial products made from woody biomass are engineered wood products. Low grade logs and wood strands are the primary raw materials for composite lumber and engineered panel products. Additional demand is coming from the rapidly growing fuel pellet industry. Competition for available clean, high quality wood fiber is intense, particularly in the Pacific Northwest.

The challenge facing potential users who gaze longingly at sources of urban biomass is how to economically recover, process the material into valuable forms, and transport precision feedstocks from residential neighborhoods, urban centers and suburban landscapes to distant users (Beatty, Farrell et al. 2004). Unfortunately, the barriers to capture, processing and use of woody biomass are large.

- The material is generally not in a form that can be used by existing wood products and energy facilities

- Equipment that is capable to produce quality feedstock is not scaled for urban and suburban contractors or community recycling centers.

- Standards and specifications for woody biomass feedstocks do not exist, or are ad hoc.

- Markets and users are not capable of receiving the volumes of woody biomass that could be produced today, and in the near future. 
- Conversion technologies for using cellulosic feedstocks, including woody biomass, for production of liquid transportation fuels are not yet commercial.

The net result of these obstacles is that millions of tons of woody biomass are going to waste each year. We need to create a new paradigm, infrastructure, and industry that are capable of tapping this woody biomass resource for economic and societal benefit. Forest engineers have the training and culture to contribute solutions to the obstacles. This paper proposes several scenarios for such an industry and discusses the implications on equipment suppliers, new businesses, and policy managers.

\section{Facets of the Woody Biomass Supply Situation}

Woody biomass is available from a number of sources, each with its own context of scale, costs, logistical complexity, and feedstock quality attributes. Some sources may be considered to be of high quality or acceptable for certain uses, but unacceptable for others. Seasonality of supply varies by type and within types. For these and other reasons, it is highly unlikely that single sources and single users will be matched. We suggest that a combination of brokerages and feedstock supply specialists will emerge as the dominant commercial entities to aggregate woody biomass from multiple sources and suppliers to meet the needs of multiple users and industries. In the long term, woody biomass in many forms will be assimilated into the commodity industrial materials markets for trading. The balance of this supply discussion is organized around a classification of woody biomass sources developed by Forest Concepts to align sources with extraction methods, material types as suited for various uses, and location within a geopolitical context. These classifications may not align with those used by the US Forest Service, Environmental Protection Agency, or US Department of Energy - each of which created classifications based on their own set of metrics.

\section{Forest Residuals (aka logging residue and slash)}

Nationally, only a small fraction of forest residuals are collected and removed from forestlands. Some amount must be left to support the habitat, organic carbon and nutritional sustainability of the landscape. The "Billion Ton Vision" (Perlack, Wright et al. 2005) concluded that approximately 41 million tons per year is available from federal, state and private forestlands, with more than 37 million tons per year coming from private forest harvests at current and projected harvest levels.

Numerous technologies are available or currently under development to collect and efficiently transport woody biomass from this source. Log forwarders and loaders have been adapted to move small diameter and brushy materials. Highly transportable grinders and shredders are available and in use across the country to produce hog fuel. Transportation from forest sites to local customers or reload centers is advancing with the development of roll-off containers (Rawlings et al. 2004), bundlers (Timberjack and Valmet in particular), and balers (Dooley et al. 2006).

Today, the market for processed forest residuals is primarily for combustion power and steam. Federal and state incentives for generation of biomass-derived power, as well as green-power programs sponsored by utilities is driving additional use. Increased demand for bio-derived power is stimulating increased consumption by existing power and steam plants as well as construction of new facilities.

Low quality of ground and shredded forest residuals is a problem for both power generators and for potential industrial and fuel producers. Quality issues include contamination with soil, grit and rocks, particle size distribution, and high moisture content. 


\section{Forest Thinning for Silvicultural Benefit and Wildfire Protection}

Private and industrial forest landowners conduct multiple thinnings, and sometimes pruning, to maximize the growth, health and yield of their forests. Plantations are typically thinned at age 710 years, and again in a pre-commercial harvest prior to complete harvest at maturity. Today, nearly all of the non-merchantable biomass is left in the forest to decay in-place. However, there is an historic base of technologies to enable recovery of thinnings provided the markets justify costs (Hartsough et al. 1994; Harder 1990; Lenane 1979).

Thinning forestland at all scales from neighborhood greenbelts to vast public lands for the purpose of reducing the risk and severity of wildfire is increasing rapidly. In many cases the costs are paid by public agencies through grant and cost reimbursement programs. Because the objective is to reduce fuel loads and make the forest more open, large trees are cut and typically all biomass beyond that needed for ecological benefits must be masticated or removed from the landscape to minimize the wildfire fuel load. While much of the material is masticated and left in the woods (Windell and Bradshaw 2000), traditional selective logging equipment such as feller-bunchers, biomass bundlers, and forwarders are used due to the large piece size and volume per unit area that must be handled.

The Billion Ton Vision estimates that nearly 60 million tons of woody biomass is available per year from forest thinning to reduce fuel loads. Although much of the equipment appropriate to this task is available commercially (Brown and Kellogg 1996; Nakamura 2004; Rich 2005; Polagye, Hodgson, and Malte 2007), the number of competent contractors is small. As in the case of forest residual grinding, the resulting hog fuel and ground woody biomass that results from forest thinning is often of poor quality and geographically distant from existing and evolving markets.

\section{Wildland Urban Interface Fuels Reduction Programs}

The wildland urban interface constitutes a special case in that the thinning units are typically very small, widely dispersed, and have the complication of houses, curious children, and domestic animals within the safety zone of most forest equipment. There are hundreds of Firewise Communities and Fire Safe Councils in more than twenty states across the United States that are engaged in organizing and executing projects. These organizations receive funding from the National Fire Plan, regional wildfire protection districts and local governments, as well as insurance companies and other sponsors. The primary activities for these nongovernmental and non-profit organizations are to educate property owners and to conduct pruning, brushing and thinning events that reduce the risk and severity of wildfires. Additionally, public landowners such as the USDA Forest Service and Bureau of Land Management invest in small-scale thinning, pruning and brush removal projects around recreation areas, resorts, and adjacent communities.

The amount of woody biomass and other fine fuels available from interface projects is increasing rapidly due to a number of factors. Most property owners do not want the material chopped or chipped and spread back on their property. Others object to the danger, noise and dust of chippers operating in residential areas. Many property owners are sophisticated enough to insist on removal of unwanted landscape vegetation, trees and brush that otherwise do not fit the fire protection prescriptions as a quid pro quo for allowing fuels reduction contractors or work crews onto their property. Additionally, increasing pressure from air quality agencies is eliminating burning of woody biomass on site. To our knowledge, all of this material is being disposed of in landfills or composted. This material is an obvious choice for recovery and recycling since it is available at roadside and in most cases today is being disposed of with a tipping fee. 
While traditional logging, macerating and thinning is spatially and economically practical in contiguous forests with established forestry infrastructure (Sirois and Stokes 1985), conventional logging methods are ill-suited to areas with a patchwork of residential lots, public spaces and forestland / brushland. At the urban interface end of the project-size spectrum are landscape companies, with very high extraction costs per unit of biomass. No less problematic is the fact that the corresponding equipment produces a limited array of end products, namely slash and / or wood chips - neither of which, in most cases, achieves sufficient efficiency to produce material that can be transferred to a commercial use at a cost-neutral or profitable rate. The diagram below - "Zen and the Art of Fuels Reduction" - provides a general overview of the spectrum of fuels reduction and who is carrying out the work at a given scale; community fuels reduction organizations are active across the spectrum, but primarily outside of the commercial lumber sector.

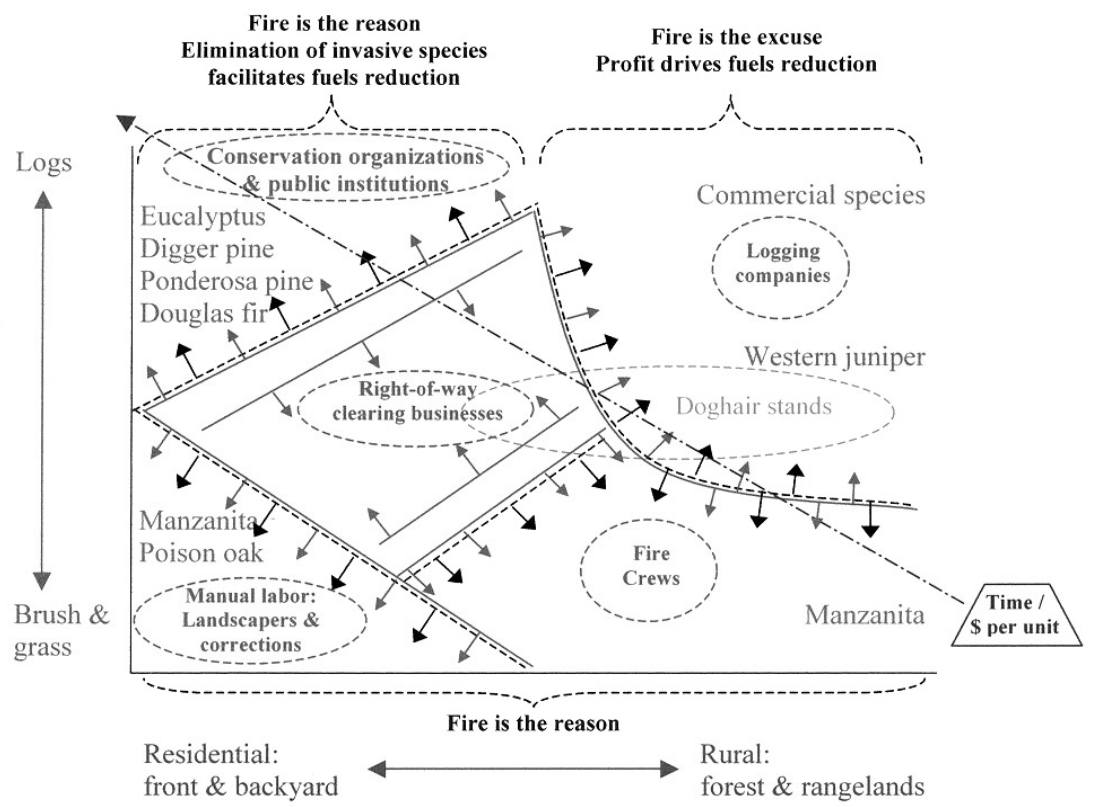

Figure 1. Zen and the Art of Fuels Reduction. This graphic depicts the material characteristics, locations for fuel reduction projects, and entities performing the fuel reduction activities.

The above graphic maps the results of a survey by Forest Concepts that included more than sixty organizations in four western states. Five different types of contractors/work crews are identified in the dotted bubbles. Each is most effective in a niche within the scale of work site and the sale of material piece size. As should be expected, the equipment, methods, and resulting biomass properties from each contractor would be different.

\section{Urban and Suburban Greenwood Woody Biomass}

Urban and suburban greenwood includes municipal and parkland tree trimmings, woody debris from landscape maintenance and green or dead woody debris from development of roads, residential areas and other elements of the built environment. The US Environmental Protection Agency (EPA) and many local government agencies have quantified this material as being of high priority for diversion from landfills. A census of wood waste available for renewable energy production concluded that 10.1 million tons of "woody yard trimmings" was available in 1998 
(Fehrs 1999). In nearly all cases, disposal of this material at composting or landfill sites involves payment of tipping fees.

Today, most of this material that is collected by contractors and landscapers is chipped in small trailer-mounted chippers and blown into vans for transport to dump sites. Chipping reduces the bulk and generally facilitates disposal. Unfortunately, landscaper chippers are not designed to produce chips of sufficient quality (length, width, thickness) to be useful for papermaking or for processing into fuel pellets or for energy fiber. A new generation of on-site processing equipment will be needed that efficiently and safely densifies this material and preserves its value for subsequent recovery and use. One such technology is baling (Lanning et al. 2007). Other technologies include new types of small scale shredders (e.g. Vermeer HG200), portable screen systems, and centralized chip reprocessing to separate valuable fractions for bulk shipment to users.

\section{Utility Corridor Maintenance, Clearing, and Trimming}

Utility corridors for pipelines, power lines, and communication cables must be kept clear of vegetation to enable maintenance, prevent wildfires from overheating the utility infrastructure, and to prevent sparks from power lines from starting wildfires. A new national energy policy is stimulating the designation and development of new and expanded regional transmission and pipeline corridors. The volume of woody biomass that could be recovered from corridors is unknown, but probably quite large. Clearing and maintenance contractors tend to be local firms who are engaged by the utilities to conduct maintenance work. They use conventional masticators, chippers and grinders to process the material for on-site scattering or off-site disposal.

At a minimum, there are $30,000 \mathrm{~km}$ (20,000 miles) of corridors that undergo maintenance brushing at least once every five years. Assuming that the average clear zone is $30 \mathrm{~m} \mathrm{(100} \mathrm{ft.),}$ then the amount of maintenance area is at least 13,000 ha (50,000 acres) per year. At a production rate of 5 ha per day, and 100 operating days per year, the minimum number of contract operations is 250 machines and operators. At a production rate of $25 \mathrm{mg} / \mathrm{ha}$ (10 t/ac) the yield of woody biomass may be on the order of $300,000 \mathrm{mg}(150,000$ tons) per year. It is likely that these estimates are low by a factor of three or more. The design of projects and equipment used for utility corridor maintenance will need to be modified to accommodate recovery of the woody biomass rather than masticate for onsite disposal.

\section{Storm Debris - Woody Debris}

The availability and quantity of woody biomass from storm debris is event dependent, both geographically and seasonally. The volume ranges from millions of tons in a concentrated area as was the case with hurricanes Katrina and Hugo to a few hundreds or thousands of tons in tornadoes and annual winter storm events. Due to the unpredictability of storm debris, the equipment and contractors used for storm cleanup are typically diverted from their usual activities in forest management, landscape and arborist services, etc.

In the case of very large storm events such as hurricanes and major wind events, downed or stockpiled woody material can be mined for a year or two before decay precludes market value. To the extent that the material can be processed into fuel, pulp chips, pellet feedstock or particle board furnish there is considerable market potential to offset the cost of processing. However, pushing large quantities of woody biomass on limited geographical markets can depress prices for traditional forest products as was the case in Washington State after the wind storms of December 2007. 
Technologies to convert storm debris and other episodic sources of woody biomass to a more storable and stable form would enable more efficient markets and better utilization. One example would be to grind the material, dry it and store it in bulk form in large sheds or tents much as hay is stored today. Another would be to process the material in relocatable pellet plants that can be set up for a few months at a location and then moved in a few days to a new site. In either case the productivity of a processing center would need to be in the hundreds to thousands of tons per day.

\section{Urban Wood Waste}

Urban wood waste is usually broadly defined to include woody debris as described above plus construction and demolition woody debris, used pallets, land clearing debris and landscape prunings (Solid Waste Association of North America 2002). For purposes of this discussion, we are defining urban wood waste to include construction and demolition waste, scrap pallets and shipping containers and other sawn or composite lumber waste. The rationale for our separate definitions is that wood waste material is comprised of products made from bole wood and the wood is dry. Processing inevitably includes separation of treated and contaminated wood from the stream, magnetic collection of steel nails and metal debris from the processed material, and ease of processing at neighborhood or otherwise fixed location processing sites. Data from 1998 estimated the volume of construction and demolition wood waste to be 35 million tons per year. Wood waste from used pallets and shipping containers is rarely reported since the material is easily processed by existing equipment into furnish for new composite wood products, and the market is robust.

\section{Industrial Wood Waste, Including Forest Industry Waste}

Industrial wood waste from primary and secondary wood products firms, industrial woodworkers (cabinetry, pallets, trusses, architectural details, etc.) as well as pulp and paper mills has been diverted to energy production and landscape mulch for many decades. The paper industry has almost always included a wood and bark fired boiler for steam and power production within a mill complex. Sawmills are less likely to include onsite cogeneration plants, favoring natural gas for thermal energy. Today, many saw mills are rethinking the potential for internal biomass power. Others are installing fuel pellet production mills to produce wood pellets for commodity sale while continuing to use natural gas for their own heating needs. Very little of the forest industry wood waste is available for new energy uses.

\section{Dedicated Woody Energy Crops}

Dedicated woody energy crops include willow, hybrid poplar, eucalyptus, bamboo, and other fast growing species. In those areas where energy crops are being planted, specialized equipment for harvest and processing are being developed (Savoie et al. 2006). As the industry matures, it is likely that feedstock specifications will narrow and more sophisticated equipment and process systems will evolve. Today, the amount of land devoted to woody energy crops is small.

\section{Intermediate Feedstocks from Woody Biomass - other than solid wood products}

We have described nearly a dozen distinct sources of woody biomass, each with unique attributes for both the physical materials and the systems for collection and processing. In this section we will discuss a few of the primary destinations for processed biomass. This discussion 
is needed because market forces will allocate biomass fractions to the highest and most profitable use based on distance between pairs of sources and users coupled with market dynamics. Even within the energy markets, the lowest market value is for hog fuel while the highest market value today is for residential grade fuel pellets. There are suggestions that the cellulosic ethanol industry will require even higher grades of woody feedstocks. Various processes for production of liquid transportation fuels are likely to have intermediate willingness to pay for feedstock.

Over the past ten years, the author has repeatedly explored the potential to subsidize energy fiber by separating and diverting high value fractions to other uses (Dooley 2002; Dooley 2005; DeTray et al. 2006; Dooley 2006; Dooley, DeTray, and Lanning 2006). In a simple example if the value of energy fiber was $\$ 25$ per ton, while the cost of delivering woody biomass to the mill was $\$ 35$ per ton, the deal is a loser unless public good in the form of a tax benefit or subsidy makes up the shortfall between market value and cost. However, if 10 percent of the volume could be diverted to small-log sawmills at $\$ 75$ per ton and 15 percent chipped into high quality pulp chips worth $\$ 85$ per ton, then the producer can make a profit while still selling the energy fiber for only $\$ 25$ and no public subsidy is necessary.

The most plausible alternative value-added markets for wood fiber that can be readily separated from the woody biomass stream include:

- Composite wood products - Particle Board, Medium Density Fiberboard (MDF), Polymer-Wood composites, Cement-Wood Fiber composites

- Pulp and paper chips

- Fuel pellets - Industrial, Residential

- Pelletized industrial feedstocks - Biorefinery, Gasification, Fermentation

- Hog fuel - Chipped and ground woody biomass for combustion energy

- Mulch and compost - Soil amendment, Growing media

Interestingly, the prices of mulch and compost are already increasing due to an imbalance between production due to diversion of feedstocks to energy and other products and demand from long-standing agricultural, horticultural and urban markets.

\section{Postulate for Future Woody Biomass Supply Industry}

The developed nations of the world are slowly converting their attitudes about woody biomass from a positioning of woody biomass as waste to a repositioning of woody biomass as a critical resource for bio-based products, industrial materials and biofuels. As we have described, the sources of woody biomass are highly fragmented, both in type and in geographic distribution. This new recognition of biomass as a resource comes at a time when the traditional forest products industry is going through a devolution into many smaller, less integrated firms, and a few very large narrowly focused industrial participants in those sectors that are extraordinarily capital intensive.

The new paradigm considers every one of the tens of millions of residential lots, parks and roadsides as sources of woody biomass. Just as the waste management industry has solved the problem of garbage collection, recyclables recovery, and greenwaste collection, woody biomass will be collected and segregated from other organic waste for consolidation and delivery to markets. In the urban centers, woody biomass should join cardboard, paper, plastic milk cartons, and aluminum cans as valued recyclables. 
The waste separation and recycling infrastructures are likely to be early adopters of new methods and equipment for recovering and packaging urban woody biomass for markets. They already have the culture and public support. A mantra that "wood is too valuable to burn, compost or dump" will be readily accepted by urban and suburban populations. Waste regulations in many communities will need to be modified to accommodate the repositioning of woody materials as resources rather than garbage.

Sophisticated distribution and logistics models will guide the siting of collection and processing facilities to enable cost-effective collection, conversion to precision feedstocks, and packing or densification for transport to local and distant users.

Conversion of urban-source woody biomass into useful bio-based products and liquid transportation fuels may well move closer to urban centers rather than be located in distant rural communities as proposed in most current models. Informed publics may buy into the notion that their tree trimmings from today are the fuel of tomorrow. They will expect that the processing facilities would be appropriately community-scaled and environmentally benign. If so, they will embrace the concept of bioproducts being produced in urban commercial centers alongside commercial bakeries and concrete plants.

At the other end of the scale, we can expect that a relatively few very large biorefineries will be sited on existing pulp mill sites, adjacent to petroleum refineries, or in communities that presently mine coal, pump oil, or produce natural gas where such operations are already essential to the community.

\section{Primary Producers - harvesters, gatherers, first-mile haulers}

Across the entire spectrum of sources from front-and-back yards, residential lots and municipal parks to vast private and public forestlands there are already tens of thousands of firms of all sizes. From independent arborists and landscapers to the multinational waste management, tree service, and industrial forestry firms, market forces will stimulate change to better collect and handle woody biomass.

Today, the typical independent landscaper collects less than 0.5 ton per day of grass, leaves, and woody trimmings. That material is dumped at a compost processor and a tipping fee is paid for the privilege. In the future, the grass clippings and green leaves will likely be wet processed through local digesters into producer gas and other products. The woody material will be reprocessed into precision feedstocks or consolidated for transport to industrial scale processors. Only the debris and waste from these processes will be available to local composters for conversion to mulch. However, the organic waste, char and other detritus of urban bioconversion facilities are likely to provide new, yet undefined feedstocks for compost and mulch producers.

At the other end of the spectrum are hog fuel contractors who process logging debris into combustion energy fuel. They may operate one or more $500-1000 \mathrm{kw}(350-750 \mathrm{hp})$ grinders, screens, truck loader and a fleet of dedicated chip vans. One processor may produce as much as $300-400$ tons per day and deliver the biomass to users within $100 \mathrm{~km}$.

The context under which technologies, equipment and methods need to be developed is one that accommodates the entire spectrum of producers. One way to think about the supply side of the woody biomass system is to allocate the total tonnage across producers of logical sizes. In the table below, we identified a plausible range of producer types by tons produced per day. 
Table 1. Postulated distribution of biomass supply firms by daily production

\begin{tabular}{|c|c|c|c|c|c|c|}
\hline Tons/day & Trucks/D & Tons/hr & tons /yr & Locations & $\begin{array}{l}\text { Combined } \\
\text { tons } / \mathrm{yr}\end{array}$ & $\begin{array}{l}\text { Processors } \\
\text { this size \& } \\
\text { larger }\end{array}$ \\
\hline 1 & 0.0 & 0.1 & 250 & 40,000 & $10,000,000$ & 56,003 \\
\hline 5 & 0.2 & 0.7 & 1,250 & 8,000 & $10,000,000$ & 16,003 \\
\hline 10 & 0.4 & 1.4 & 2,500 & 4,000 & $10,000,000$ & 8,003 \\
\hline 25 & 1.0 & 3.6 & 6,250 & 1,600 & $10,000,000$ & 4,003 \\
\hline 50 & 2.0 & 7.1 & 12,500 & 800 & $10,000,000$ & 2,403 \\
\hline 75 & 3.0 & 10.7 & 18,750 & 533 & $10,000,000$ & 1,603 \\
\hline 100 & 4.0 & 14.3 & 25,000 & 400 & $10,000,000$ & 1,070 \\
\hline 150 & 6.0 & 21.4 & 37,500 & 267 & $10,000,000$ & 670 \\
\hline 250 & 10.0 & 35.7 & 62,500 & 160 & $10,000,000$ & 403 \\
\hline 500 & 20.0 & 71.4 & 125,000 & 80 & $10,000,000$ & 243 \\
\hline 750 & 30.0 & 107.1 & 187,500 & 53 & $10,000,000$ & 163 \\
\hline 1000 & 40.0 & 142.9 & 250,000 & 40 & $10,000,000$ & 110 \\
\hline 1500 & 60.0 & 214.3 & 375,000 & 27 & $10,000,000$ & 70 \\
\hline 2000 & 80.0 & 285.7 & 500,000 & 20 & $10,000,000$ & 43 \\
\hline 3000 & 120.0 & 428.6 & 750,000 & 13 & $10,000,000$ & 23 \\
\hline 4000 & 160.0 & 571.4 & $1,000,000$ & 10 & $10,000,000$ & 10 \\
\hline
\end{tabular}

The table above was constructed based on the following arguments:

Tons per day

- Independent landscapers and brush clearing firms, as well as commercial crews from larger firms use pickup trucks or one-ton trucks for their daily work. On most days they will collect much less than one ton of material. At the present resolution of analysis, one ton per day is a reasonable minimum scale.

- At the other end of the scale, the largest pulp mills in North America receive and process 2,000 to 4,000 tons of logs and chips per day.

- Intermediate producer sizes in tons per day are based on an analysis of the production rates for chippers and wood processors manufactured by Morbark, Peterson Pacific, Vermeer, Bandit, and other companies.

Truckloads per day

- We simply divided the tons per day by 25 tons per truckload to estimate the number of highway legal truckloads that would be produced or received per day. The use of the term truckloads is not well correlated with the number of vehicles delivering woody biomass per day since different contexts and sources will tend to have smaller or larger payloads. However, if a producer was to attempt to consolidate their own woody biomass into highway legal payloads for long-haul delivery to users, the number of truckloads per day would be useful.

- If we are considering receivers of biomass at a central processing site or user facility, then the rate at which trucks are received and unloaded can be estimated.

Tons per hour / Tons per year

- Tons per hour was estimated by dividing the number of tons per day by 7 hours per day. This is not entirely accurate for large facilities that operate 24 hours per day. However, it 
is likely to be an accurate assessment of the peak hourly receiving rate during the noon to 6 PM time period.

- Tons per year is estimated based on 250 operating days per year. This value is useful at the small scale to estimate space, costs and revenues for neighborhood woody materials recycling centers, and gross revenue for intermediate producers.

Locations

- The number of locations, or producers/receivers, is estimated by allocating 10 million tons per year of the annual woody biomass available to each increment of producer/receiver size. The total combined woody biomass volume of 150 million tons per year is close to the estimates included in Perlack, et. al. (2005). The 150 million tons per year multiplied by an average producer-level market value of woody biomass at $\$ 35$ - $\$ 50$ per ton suggests that the woody biomass supply industry will be $\$ 5.5$ to 8 billion per year.

- This is an order-of-magnitude estimator at best. However, the estimate of 40,000 small producers in the United States fits well with the number of arborists and landscapers who hold business licenses. At the other end of the spectrum, there are approximately 120 pulp mills in the United States that process more than 1,000 tons per day, with the largest few processing 4,000 tons per day.

Processors this size and larger

- This column suggests that there are or will be approximately 56,000 individuals and firms involved in the woody biomass supply system, with 1,000 of those producing more than 100 tons per day $(25,000$ tons per year).

\section{Consolidators, Brokers, and Logistics Specialists}

Nearly every industry that involves many small and medium sized producers and relatively large concentrated customers has a well developed network of consolidators, brokers and logistics specialist firms. In agriculture those tend to be cooperatives, commodities brokers, and freight companies. In the forest products industry there are log and chip brokers and consulting foresters who coordinate the selling of logs for large numbers of non-industrial forest landowners. The recycling industry is well staffed with brokers for everything from scrap steel to corrugated shipping containers, pallets, and waste paper.

As the woody biomass supply market evolves and matures, brokers and specialists will evolve with it - probably first by those who already have an established based in the forest products and waste management sectors. Others will evolve from brokering other urban recyclables to add woody biomass users to their suite of destinations.

\section{Precision Feedstock Processors}

The need for precision feedstock processors is increasing due to the decomposition of the industrial forest products industry and the increasing variety of woody biomass types coming on the market. For those planning new wood products facilities such as polymer-composite lumber and biorefineries for ethanol and other liquid transportation fuels, the opportunity to eliminate the "dirty end" (aka woodyard) of their chemical process facilities saves capital, management and complexity (Dooley 2006).

Very few such processors exist today. One example from the Seattle area is a twenty-person firm that processes approximately 100,000 tons per year of urban woody debris, wood waste 
and related wood fiber into more than 40 unique product feedstocks that are sold to nearly one hundred industrial and commercial customers.

The success of existing wood processors depends on savvy management and application of known technology for wood segregating, grinding and post-grinding sorting. Technology and equipment for separation of even more precise feedstocks for composite wood products, fuel pellets and some liquid fuel facilities do not yet exist.

\section{Implications for Development, Business, and Equipment}

The discussion within this paper suggests that woody biomass supply will expand from forest products industry residuals and logging debris to include suburban and urban sources. Forest sources will increasingly include woody co-products of wildfire protection, forest health improvement and forest management. These changes will inevitably result in changes within existing wood collection and processing firms, as well as establishment of many thousands of new participants. As estimated earlier, the market value of woody biomass is likely to be in the range of $\$ 5-8$ billion at the producer level. Once trucking, brokering and precision feedstock processing is added, the industry gross revenue may well approach $\$ 20$ billion within the first ten years.

The rate of growth will be dependent upon a number of factors. Today the cost and complexity of collection and transport is excessive. Collection, transport and processing technologies must be concurrently developed to enable efficient delivery of precision feedstocks to users. Today, the market specifications for precision feedstocks for composite-polymer products, cellulosic ethanol, and pyrolytic gasification to produce other liquid fuels and industrial chemicals are lacking. Today, process technologies for cellulosic ethanol and other biorefinery facilities are not yet commercial at a scale that can absorb even the most readily available woody biomass.

The United States Department of Energy roadmap for technology development suggests that the next major milestones to address the foregoing limitations are to be achieved by 2012 (DOE (U.S. Department of Energy) 2003). Pilot projects are now underway with DOE and USDA funding to demonstrate select process and conversion technologies at a limited scale.

\section{Process, Equipment, and Systems Development}

It should be readily apparent to engineers and product managers involved in the recycling, forest equipment and transportation industries that there are many gaps between the features of existing equipment, processes and systems and those that will be needed to achieve the goal of 150 million tons per year additional woody biomass utilization.

Several agencies and firms are developing baling technology and equipment to facilitate the collection and transport of small diameter woody brush and pruning debris. Baled biomass preserves piece size to enable downstream processing into targeted feedstocks, and improves the density for storage and transport (Lanning et al. 2007). Implementation of baled biomass will entail purchase of new equipment by firms that now use chippers and purchase of bale handling equipment by consolidators, haulers, and receivers. Thus, the direct impact of baling will be new equipment classes in the marketplace, plus incremental demand for existing bale handling equipment and systems. Other major feedstock equipment and systems needs are related to material sorting, fractionation, quality assessment and grinding. 


\section{Business Models and Business Formation}

Community recycling centers will adapt their business models and facility needs to accommodate woody biomass along with other recyclables. Waste management collectors and haulers will increasingly approach woody biomass under an expanded definition than pallets, construction debris and other historic recyclable wood sources. Most importantly, many new players are likely to enter the woody biomass collection, processing and hauling business. A few new business types and models were proposed in this paper. However, creative individuals and entrepreneurial firms will undoubtedly devise effective new business models to profit from increased demand for cellulosic fiber, including woody biomass.

\section{Conclusion}

This discussion paper sought to inform conversations about the evolution and technological advances related to woody biomass as a feedstock for emerging bio-economies. Several hundred million tons of woody biomass are available from all sources in the United States. Much of what was presented here applies to other nations and regions of the globe. We look to others to adapt the discussion to their contexts.

We offered a model of how many participants of various scales. The model is based on more than thirty years experience in product and business development by the author. We can expect, just in North America, the need for equipment, systems and infrastructure to support many thousands of firms in the biomass supply industry. Many will be small operators, with relatively few mega-businesses. Assistance from forest engineers, business managers, equipment companies, and the financial community must be appropriate for the full range of participants in order to meet the demand for woody biomass by producers of composite wood products, solid fuels, liquid fuels and other industrial bio-based materials.

\section{Acknowledgements}

Development was supported in-part by the CSREES Small Business Innovation Research program of the U.S. Department of Agriculture, grant numbers 2005-33610-15483, 2006-3361017595, and 2008-33610-1880.

\section{References}

Beatty, K., D. Farrell, M. John, I. Winstanley, and J. Carlson. 2004. Recovery and recycling of wood waste in King County. Seattle, WA: King County Department of Natural Resources, Solid Waste Division, 2001 South Jackson St., Ste. 701, Seattle, WA 98104.

Brown, C.G., and L.D. Kellogg. 1996. Harvesting economics and wood fiber utilization in a fuels reduction project: a case study in eastern Oregon. Forest Products Journal 46:45-52.

DeTray, M.S., J.H. Dooley, D.N. Lanning, and J.L Fridley. 2006. Perspectives on woody biomass for value-added uses in the Western United States. Paper presented at 2006 ASABE International Conference. St. Joseph, MI: ASABE.

DOE (U.S. Department of Energy). 2003. Roadmap for Agricultural Biomass Feedstock Supply in the United States. DOE/NE-ID-11129. Washington, DC: U.S. Department of Energy.

Dooley, J. H. 2002. Rural economic development through integrated smallwood forest products centers. ASAE Paper 025006. St. Joseph, MI: American Society of Agricultural Engineers. 
2005. Appropriate technology biomass collection and handling systems for smallwood utilization. USDA/CSREES/SBIR Final Phase I Report. Federal Way, WA: Forest Concepts, LLC.

2006. Feeding the biorefinery: Feedstock specifications at the interface of the dirty end and the white coat process. Invited presentation - Session 220: Biorefineries Barriers to Development. Paper read at ASABE Annual International Meeting, July 9-12, at Portland, OR.

Dooley, J.H., M.S. DeTray, and D.N. Lanning. 2006. Technology to enable utilization of biomass from wildland-urban interface fuels reduction projects. Phase II: Field evaluation of baling vs. chipping. . Auburn, WA: Forest Concepts, LLC.

Dooley, J.H., J.L Fridley, M.S. DeTray, and D.N. Lanning. 2006. Large rectangular bales for woody biomass. Paper No. 068054. St. Joseph, MI: ASABE.

Fehrs, J.E. 1999. Secondary mill residues and urban wood waste quantities in the United States. Washington, DC: Northeast Regional Biomass Program. CONEG Policy Research Center, Inc. 400 North Capitol Street, Ste. 382. Washington, DC. 20001.

Harder, Paul B. 1990. Mechanical processing keys small-tree logging job. Forest Industries 117 (9):10-11.

Hartsough, B.R., J.F. McNeel, T.A. Durston, and B.J Stokes. 1994. Comparison of mechanized systems for thinning ponderosa pine and mixed conifer stands. St. Joseph, MI: ASAE.

Lanning, D.N., J.H. Dooley, M.S. DeTray, and C. Lanning. 2007. Engineering factors for biomass baler design. ASABE Paper No. 078047. St. Joseph, MI: American Society of Agricultural and Biological Engineers.

Lenane, I. 1979. Thinning steep country using plastic chutes. Logging Industry Research Association Technical Release 2 (1):1-4.

Nakamura, G. 2004. Biomass thinning for fuel reduction and forest regeneration - Issues and opportunitites. Davis, CA: University of California Cooperative Extension.

Perlack, R.D., L.L. Wright, A. Turhollow, R.L. Graham, B.J. Stokes, and D.C. Erbach. 2005. Biomass energy feedstock for a bioenergy and bioproducts industry: The technical feasibility of a billion-ton annual supply. ORNL/TM-2005/66. Oak Ridge, TN: Oak Ridge National Laboratory.

Polagye, B.L., K.T. Hodgson, and P.C. Malte. 2007. An economic analysis of bio-energy options using thinnings from overstocked forests. Biomass \& Bioenergy 31:105-125.

Rawlings, C., B. Rummer, C. Seeley, C. Thomas, D. Morrison, H. Han, L. Cheff, D. Atkins, D. Graham, and K. Windell. 2004. A study of how to decrease the costs of collecting, processing and transporting slash. Missoula, MT: Montana Community Development Corporation.

Rich, B. 2005. Thinning, fuel manipulation and prescribed fire in dry forest types. Missoula, MT: Montana Department of Natural Resources.

Savoie, P., L. D'Amours, F. Lavoie, G. Lechasseur, and H. Joannis. 2006. Development of a cutter-shredder-baler to harvest long-stem willow. ASABE Paper 061016. St. Joseph, MI: ASABE.

Sirois, D.L., and B.J. Stokes. 1985. Preparation of wood for energy use. In Proceedings of the 5th annual solar \& biomass workshop. Tifton, GA. Washington, DC: U.S. Department of Agriculture Research Service. 
Solid Waste Association of North America. 2002. Successful approaches to recycling urban wood waste. General Technical Report FPL-GTR-133. Madison, WI: USDA Forest Service, Forest Products Laboratory.

Western Governors' Association. 2006. Clean and Diversified Energy. Biomass Task Force Report. January 2006: Western Governors' Association.

Windell, K., and S. Bradshaw. 2000. Understory biomass reduction methods and equipment catalog. Tech Report 0051-2826-MTDC. Missoula, MT: USDA Forest Service, Missoula Technology and Development Center. 